\title{
(-)-Epigallocatechin-3-gallate inhibits invasion and migration of salivary gland adenocarcinoma cells
}

\author{
JONG-HWAN PARK ${ }^{1}$, JI-HYE YOON ${ }^{1}$, SOO-A KIM ${ }^{2}$, SANG-GUN AHN ${ }^{1}$ and JUNG-HOON YOON \\ ${ }^{1}$ Department of Pathology, School of Dentistry, Chosun University, Gwangju 501-759; ${ }^{2}$ Department of \\ Biochemistry, Dongguk University College of Oriental Medicine, Gyeongju 780-714, Korea
}

Received August 19, 2009; Accepted November 10, 2009

DOI: 10.3892/or_00000673

\begin{abstract}
Epigallocatechin-3-gallate (EGCG) has inhibitory effect on a variety of cancers by inducing apoptosis and cell cycle arrest or inhibiting angiogenesis and metastasis. EGCG has been found to induce apoptosis in salivary gland carcinoma cells, however, it is not known whether EGCG affects invasion and migration. Thus, this study was performed to clarify whether EGCG affects invasion and migration of salivary gland tumors. Matrigel invasion assay, wound scratch assay and migration assay using commercial kit were performed. $\beta 1$ integrin expression and activation of its downstream molecules such as focal adhesion kinase (FAK), AKT and extracellular signal-regulated kinase (ERK) were examined by Western blot. Enzymatic activity of matrix metalloprotease (MMP)-2 and MMP-9 was examined by gelatin zymography. EGCG inhibited effectively invasion and migration of SGT cells in a dose-dependent manner. EGCG also inhibited the activation of $\beta 1$ integrin-downstream molecules such as FAK, AKT and ERK as well as the expression of $\beta 1$ integrin itself. Moreover, MMP-2 and MMP-9 expression and their enzymatic activity were reduced by EGCG in a dose-dependent manner. These results indicate that EGCG may effectively suppress salivary gland tumors by inhibiting metastasis through $\beta 1$ integrinmediated signaling.
\end{abstract}

\section{Introduction}

Salivary gland cancers account for $<0.5 \%$ of all malignancies and approximately 3-6\% of all head and neck tumors in adults (1-3). Little is known about the etiology of salivary gland cancers. Radiation exposure and a history of any prior cancer are the established risk factors for salivary gland tumors (4-6). Epstein-Barr virus can be a factor for the

Correspondence to: Dr Sang-Gun Ahn or Dr Jung-Hoon Yoon, Department of Pathology, School of Dentistry, Chosun University, 375 Seosuk-dong, Dong-gu, Gwangju 501-759, Korea

E-mail: ahnsg@chosun.ac.kr

E-mail: jhyoon@chosun.ac.kr

Key words: (-)-epigallocatechin-3-gallate, salivary gland tumor, invasion, migration, $\beta 1$ integrin development of lymphoepithelial salivary gland tumors (7). The WHO classification of malignant salivary gland tumors has been recently updated, listing 24 different histologic subtypes (8). The main four histopathologic types include mucoepidermoid carcinoma (29-34\% of malignant tumors), adenoid cystic carcinoma (about 20\%), adenocarcinoma and salivary duct carcinoma.

Salivary gland carcinomas are primarily managed with surgical resection, often in conjunction with postoperative radiation therapy (9). The functions of chemotherapy in the management of salivary gland cancers remain unsolved (2). Chemotherapy is generally indicated only for palliation in symptomatic patients with recurrent and/or unresectable cancers (9), because response rates of salivary gland cancers to chemotherapy are inconsistent, varied and generally poor (10).

Green tea is one of the most popular beverages in the world because it has many beneficial effects on human health. It contains many catechins such as (-)-epigallocatechin-3gallate (EGCG), (-)-epigallocatechin (EGC), (-)-epicatechin3 -gallate (ECG) and (+)-catechin (11). EGCG is the most abundant polyphenol in green tea and has been found to inhibit growth of tumor cells by inducing apoptosis or inhibiting angiogenesis $(12,13)$. In addition, EGCG inhibits invasion and metastasis of a variety of tumor cells (14-17). Sakagami's group showed that EGCG induced apoptosis of human salivary gland tumor HSG $(18,19)$. However, there is no report about the effect of EGCG on invasion and migration of salivary gland tumor. Therefore, in this study, we examined the effect of EGCG on adhesion, invasion and migration of salivary gland adenocarcinoma SGT cells.

\section{Materials and methods}

Cell culture. SGT human salivary gland adenocarcinoma cells (a gift from Professor C.H. Lee, Dankook University) (20) were cultured in Dulbecco's modified Eagle's medium (DMEM) supplemented with $10 \%$ fetal bovine serum, $100 \mu \mathrm{g} /$ $\mathrm{ml}$ streptomycin and 100 units $/ \mathrm{ml}$ penicillin at $37^{\circ} \mathrm{C}$ in a $5 \%$ $\mathrm{CO}_{2}$ incubator.

MTT assay. To determine a concentration to be used in the further experiment, cell viability was examined using the MTT assay. The cells were seeded at $3 \times 10^{5}$ cells $/ \mathrm{ml}$ into the 12-well plates and treated with different concentrations of 
EGCG (Cayman Chemical Co., Ann Arbor, MI) for $24 \mathrm{~h}$. Cells were washed twice with ice-cold PBS, and $0.5 \mathrm{ml}$ of cell culture medium and $50 \mu 1$ of 3-(4,5-dimethylthiazol-2-yl)2,5-diphenylte-trazolium bromide reagent $(5 \mathrm{mg} / \mathrm{ml}$ in PBS) were added and incubated for $3 \mathrm{~h}$ at $37^{\circ} \mathrm{C}$. The media were then removed and $250 \mu 1$ of acid-isopropanol $(0.04 \mathrm{~mol} / \mathrm{l} \mathrm{HCl}$ in isopropanol) was added. The optical density (OD) was then measured by a Microplate Autoreader ELISA (Bio-Tek Instruments, Inc., Winooski, VT) at $570 \mathrm{~nm}$ wavelength.

Matrigel invasion assay. Cell invasion assay was performed using a Matrigel invasion assay kit (BD Biosciences, San Jose, CA) according to the manufacturer's instructions. Briefly, serum-free media supplemented with EGCG was added to the well. Cells were seeded in the insert of the transwell plate and incubated for $22 \mathrm{~h}$ at $37^{\circ} \mathrm{C}$. The cells that invaded to the lower surface of the membrane were fixed with methanol and stained with hematoxylin for $5 \mathrm{~min}$. On microscopy, five areas from each sample were randomly selected and invasion cells were counted as previously described (21).

Wound-scratch assay. The cells were allowed to grow in culture dish overnight and a scratch about $3 \mathrm{~mm}$ in width was made of in monolayer by yellow tip. After washing twice with PBS, the cells were cultured in the absence or presence of EGCG, and photographs were taken in series at different time-points.

Cell migration assay. Cell migration assay was performed using a Chemotaxis Cell Migration Assay kit (Chemicon) according to the manufacturer's instructions. Briefly, EGCG was treated in culture media outside of the insert. The cells were added to the insert and incubated for $24 \mathrm{~h}$. The migrated cells to the lower surface of the membrane were processed and counted as described in invasion assay. To quantify migration ability, migrated cells are lysed using the cell lysis buffer and optical density was measured with the CyQUANT GR Dye using fluorescence plate reader (Varioskan, Thermo Electron Co., Waltham, MA) at 480/520 nm.

Western blot analysis. After treated with EGCG, the cells were lysed in lysis buffer $(137 \mathrm{mM} \mathrm{NaCl}, 15 \mathrm{mM}$ EGTA, $0.1 \mathrm{mM}$ sodium orthovanadate, $15 \mathrm{mM} \mathrm{MgCl}, 0.1 \%$ Triton $\mathrm{X}-100,25 \mathrm{mM}$ MOPS, $100 \mu \mathrm{M}$ phenylmethylsulfonyl fluoride and $20 \mu \mathrm{M}$ leupeptin, adjusted to $\mathrm{pH}$ 7.2). The total protein (40-50 $\mu \mathrm{g}$ per lane) was resolved by $7.5-15 \%$ SDS-PAGE and transferred onto PVDF membranes. After blocking in TBS (20 mmol/l Tris, $137 \mathrm{mmol} / \mathrm{l} \mathrm{NaCl}, 1 \mathrm{~g} / \mathrm{l}, \mathrm{pH}$ 7.6) with $5 \%$ skim milk for $2 \mathrm{~h}$ at room temperature, the membranes were incubated with primary antibodies at $37^{\circ} \mathrm{C}$ overnight. Antibodies of $B 1$ integrin, focal adhesion kinase (FAK), pFAK, matrix metalloprotease (MMP)-2, and MMP-9 were from Santa Cruz Biotechonology (Santa Cruz, CA). In addition, antibodies of Akt, pAkt, extracellular signal-regulated kinase (Erk) and pErk were from Cell Signaling (Danvers, MA). The membranes were then washed three times with a $0.05 \%$ tween-TBS (TBS-T), followed by incubation for $1 \mathrm{~h}$ with secondary antibodies (1:5000; Santa Cruz Biotechnology) at room temperature. Finally, the membranes were visualized using the West ZOL Plus detection reagent in the LAS-1000 (Fujifilm, Japan).

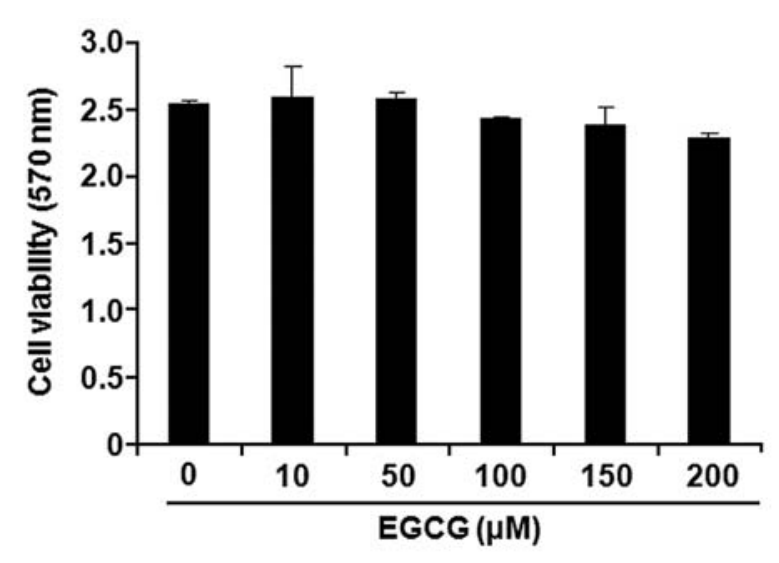

Figure 1. SGT cells were incubated with various doses of EGCG $(10,50,100$, 150 and $200 \mu \mathrm{M}$ ) for $24 \mathrm{~h}$ and cell viability was measured by MTT assay.

$R T-P C R$. The primer sets used in this study were as follows. ß1 integrin, F:5'-ATGCCTACTTCTGCACGATGTG-3', R:5'-GATGGCATCGAAACCACCTTCT-3'; MMP-2, F:5'-CT TCCAAGTCTGGAGCGATGT-3', R:5'-TCTCCCAAGGTC CATAGCTCA-3'; MMP-9, F:5'-CCTGCAACGTGAACAT CTTCG-3', R:5'-GCCTGTGTACACCCACACCTG-3'; GAPDH, F:5'-CCAAGGTCATCCATGACAACT-3', R:5'GTCATACCAGGAAATGAGCTTGACA-3'. cDNA synthesis and reverse-transcription polymerase chain reaction (RT-PCR) were performed from $2 \mu \mathrm{g}$ total RNA using an One Step RT-PCR kit (iNtRON Biotechnology, Seongnam, Korea). The PCR condition consisted of an initial denaturation at $94^{\circ} \mathrm{C}$ for $2 \mathrm{~min} ; 30$ cycles of $94^{\circ} \mathrm{C}$ for $15 \mathrm{sec}, 55^{\circ} \mathrm{C}$ for $30 \mathrm{sec}$ and $72^{\circ} \mathrm{C}$ for $1 \mathrm{~min}$; a final extension at $72^{\circ} \mathrm{C}$ for $10 \mathrm{~min}$. The PCR products were separated on a $1.2 \%$ agarose gel, visualized and photographed using a gel documentation system.

Gelatin zymography. MMP-2 and MMP-9 enzymatic activities were assayed by gelatin zymography. Supernatants from EGCG-treated cultures were electrophoresed on an $8 \%$ SDSPAGE containing gelatin. The gel was washed three times with renaturating buffer, followed by a brief rinsing in distilled water, and then incubated with development buffer at $37^{\circ} \mathrm{C}$. After incubation, the gel was stained with Coomassie Brilliant Blue G250 (0.1\% in 25\% methanol and $10 \%$ acetic acid in water) and destained in the same solution in absence of the dye (22).

Statistical analysis. The differences in mean values among different groups were tested, and the values were expressed as mean $\pm \mathrm{SD}$. All of the statistical calculations were carried out using Microsoft Excel. Values of $\mathrm{P}<0.05$ were considered significant.

\section{Results}

Effect of EGCG on the viability of SGT cells. To determine a concentration to be used in the further experiments, the cell viability was examined by MTT assay at the absence or presence of EGCG. Cell viability was slightly decreased by EGCG in a manner dependent on dose, but which is not significant (Fig. 1). Even at the highest concentration $(200 \mu \mathrm{M})$, 
A

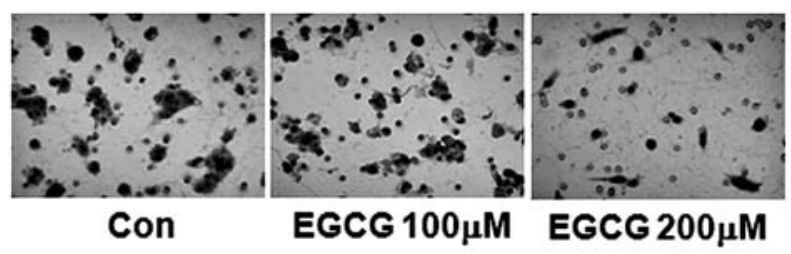

B

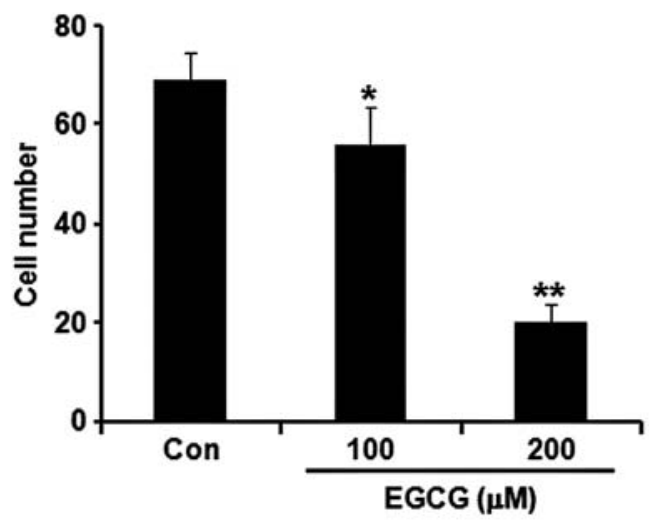

Figure 2. Matrigel invasion assay was performed to examine the effect of EGCG on the invasiveness of SGT cells. The cells were cultured at the absence or presence of EGCG (100 and $200 \mu \mathrm{M})$ for $24 \mathrm{~h}$. The cells that invaded to the lower surface of the membrane were fixed and stained with hematoxylin and photographs were obtained from each sample (A). On microscopy, five areas from each sample were randomly selected and invasion cells were counted (B). Results are expressed as mean $\pm \mathrm{SD} .{ }^{*} \mathrm{P}<0.05$, ${ }^{* *} \mathrm{P}<0.001$.
EGCG induced only about $10 \%$ decrease of viability of SGT cells. Therefore, we determined to use 100 and $200 \mu \mathrm{M}$ EGCG in further experiments.

Effect of EGCG on invasion and migration of SGT cells. Cell invasion and migration are of fundamental importance in tumor metastasis and angiogenesis $(23,24)$. Therefore, we examined the effect of EGCG on invasion and migration of SGT cells. Treatment of EGCG significantly reduced the number of invading cells in a dose-dependent manner (Fig. 2). Cell migration was evaluated by two systems including woundscratch assay and cell migration assay using a commercial kit. The migration of SGT cells across the wounded space was inhibited by EGCG in a time- and dose-dependent manner (Fig. 3A and B). Moreover, the number of cells passing though membrane was dose-dependently decreased by EGCG (Fig. 3C and D). When the migrated cells were lysed and incubated with green-fluorescent dye, which bound to cellular nucleic acids, optical density was also diminished by EGCG in a dose-dependent manner (Fig. 3E). These findings suggest that EGCG suppressed effectively invasion and migration of SGT cells.

Effect of EGCG on the expression of down regulators of $\beta 1$ integrin. Cell adhesion to extracellular matrix (ECM) is mediated by integrins that play a significant role in tumor progression and metastasis (25). Therefore, we examined the effect of EGCG on the expression of $\beta 1$ integrin and its downstream molecules. The expression of cell surface $\beta 1$ integrin
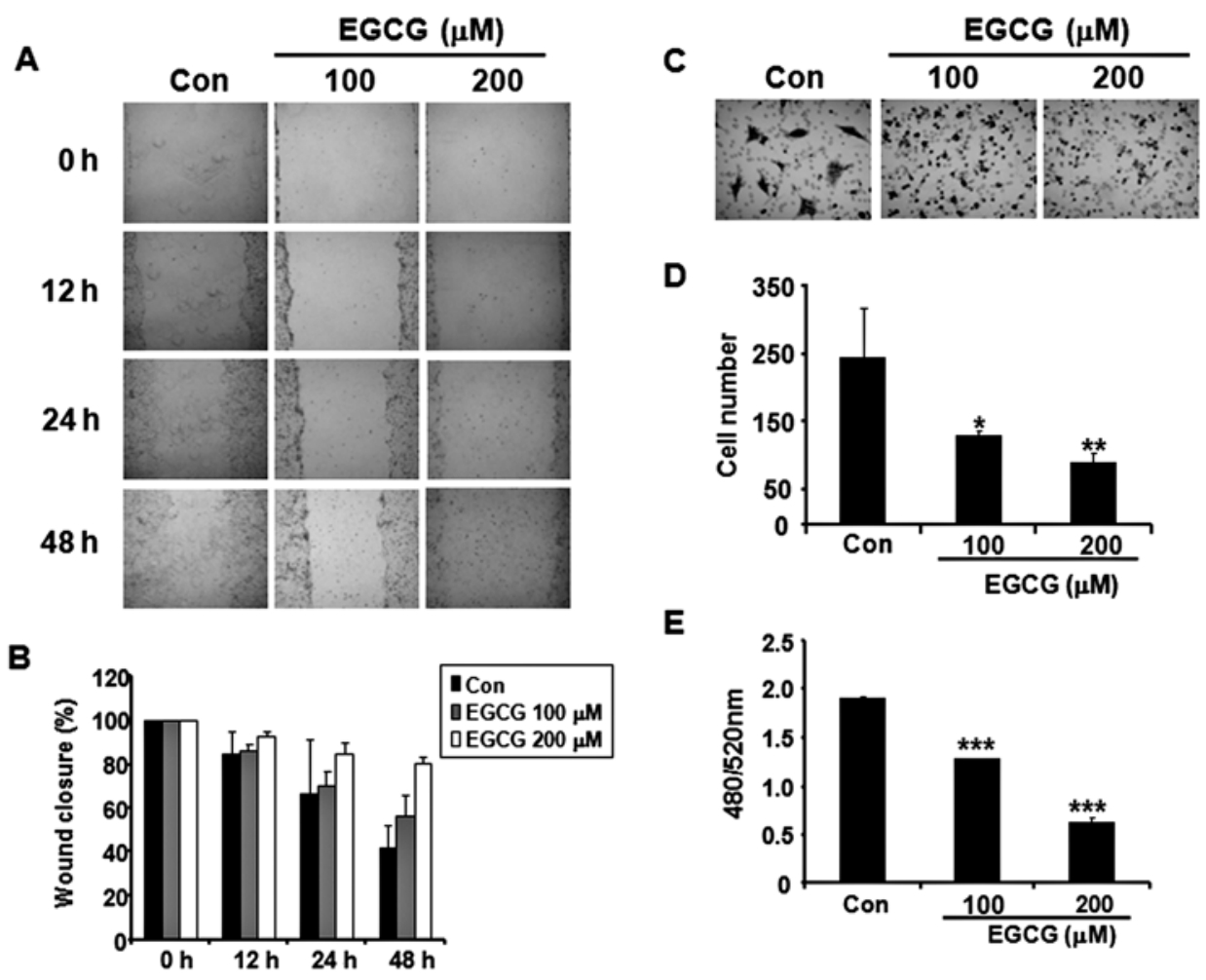

D

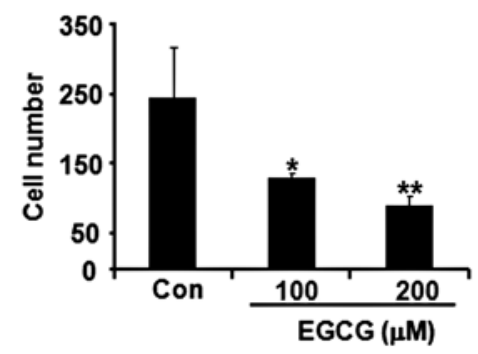

E

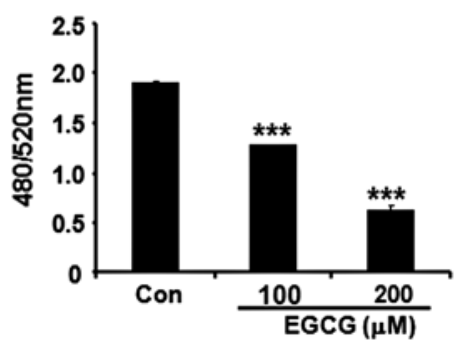

Figure 3. After the cells were fully grown, wound scratch about $3 \mathrm{~mm}$ in width was made in the cell culture dish. The cells were then incubated at the absence or presence of EGCG and photographs were taken from each sample at various time-points (A). The length between each wound edge was measured and the wound closure was expressed as percentage compared with the length of first made wound edge (B). As another experiment to examine the effect of EGCG on the migration of SGT cells, cell migration assay was performed. The migrated cells to the lower surface of the membrane were processed and stained. Photograph was taken from each sample (C) and migrating cells were counted as described in invasion assay (D). To quantify migration ability, migrated cells are lysed using the cell lysis buffer and optical density was measured at $480 / 520 \mathrm{~nm}(\mathrm{E})$. Results are expressed as mean $\pm \mathrm{SD}$. ${ }^{*} \mathrm{P}<0.05,{ }^{* *} \mathrm{P}<0.01,{ }^{* * *} \mathrm{P}<0.001$. 


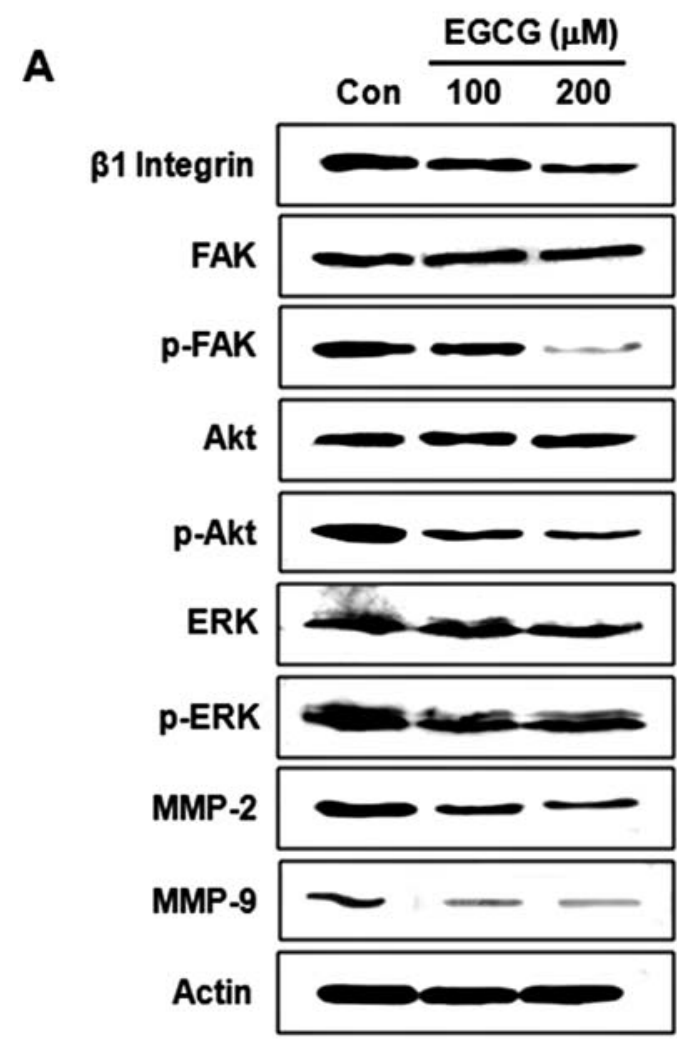

B

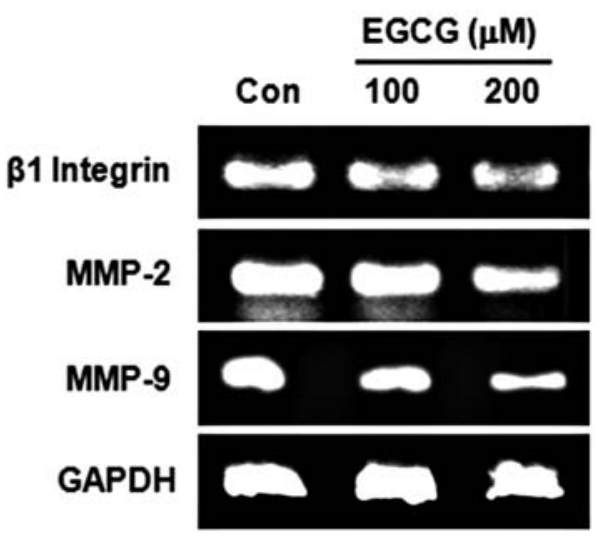

Figure 4. The cells were incubated for $24 \mathrm{~h}$ at absence or presence of EGCG and subsequently, protein and mRNA were extracted from each sample. Western blot analysis was performed to examine the expression of $\beta 1$ integrin, MMP-2 and MMP-9 and the activation of FAK, AKT and ERK (A). mRNA levels of ß1 integrin, MMP-2 and MMP-9 were examined by RT-PCR (B).

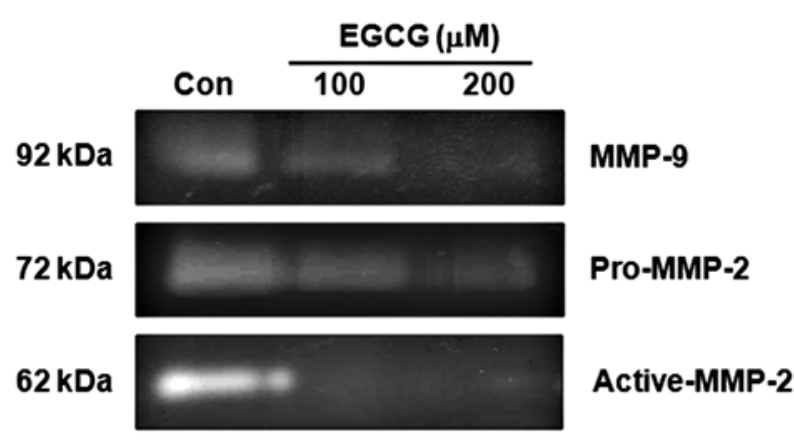

Figure 5. The cells were treated with EGCG for $24 \mathrm{~h}$. Each conditioned media was collected, and then was analyzed for the gelatinolytic activities of MMP-2 and MMP-9 by zymography.

was decreased by EGCG (Fig. 4A). Phosphorylation of FAK, Akt, and Erk was also reduced by EGCG in a dose-dependent manner (Fig. 4A). Moreover, EGCG also inhibited the expression of MMP-2 and MMP-9 in a dose-dependent manner (Fig. 4A). To examine whether EGCG affects the steady-state levels of $\beta 1$ integrin, MMP-2 and MMP-9 mRNAs, RT-PCR was performed. The level of mRNA expressions for B1 integrin, MMP-2 and MMP-9 was also reduced by EGCG in a dose-dependent manner (Fig. 4B).

Effect of EGCG on activities of MMP-2/-9. Extracellular matrix breakdown is pivotal for cellular invasion, indicating that matrix-degrading proteinases are essential for tumor cell metastasis (26). Therefore, we determined the activity of MMP-2 and MMP-9 by gelatin zymography after $24 \mathrm{~h}$ incubation with EGCG in SGT cells. As shown in Fig. 5, treatment of EGCG suppressed the gelatinolytic activities of MMP-2 and MMP-9 of SGT cells in a dose-dependent manner.

\section{Discussion}

Many scientists are interested in natural products because of their various beneficial effects on human health such as antiinflammation and anti-cancer properties. EGCG, the most abundant catechin in green tea, has been widely studied regarding its beneficial effects on health including anticancer effect. EGCG exhibits anti-cancer effect by inducing apoptosis and cell cycle arrest or inhibiting angiogenesis and metastasis (27). It also inhibits the signal transduction pathway related to tumorigenesis such as mitogen-activated protein kinase (MAPK), the activator protein 1 (AP-1), nuclear factor $\kappa \mathrm{B}(\mathrm{NF}-\kappa \mathrm{B})$, epidermal growth factor receptor (EGFR) or insulin-like growth factor-1 (IGF-1) mediated pathway (27).

Although previous studies revealed that EGCG induced apoptosis of salivary gland carcinoma cells (HSG), its antiinvasion and anti-migration effects on salivary gland malignancies were not reported. In the present study, we showed that EGCG exhibits anti-invasion and anti-migration effect on SGT cells at the concentrations showing little cytotoxicity. EGCG has been reported to inhibit invasion and metastasis of a variety of cancer cells (14-17). Moreover, 
EGCG inhibited adhesion and migration of stromal cells such as fibroblasts (28). These findings indicate that EGCG may generally affect adhesion, invasion and migration in a variety of cell types.

The major mechanisms of cancer invasion and migration are that primary cancer cells disseminate and grow at a distant site resulting in a secondary tumor (29). When cancer cells invade and migrate, various proteolytic enzymes contribute to the degradation of extracellular matrix (ECM) $(22,30)$. Integrin receptors play critical roles in cell-to-cell contacts, cell adhesion and migration, and major receptor for cell adhesion and ECM (31). Among the integrins, $\beta 1$ integrin is known to mediate cell adhesion and migration (32-34). Focal adhesion kinase (FAK) has been shown to regulate integrinmediated signaling $(31,35)$. After ligand stimulation or integrin engagement, FAK becomes phosphorylated, which leads to the phosphorylation of down regulators such as Akt and Erk. Subsequently, activation of these signaling molecules leads to increase of matrix metalloproteinase (MMP) production, promoting invasion of migration of tumor cells (36-40). Among the MMPs, MMP-2 (gelatinase-A) and MMP-9 (gelatinase-B) are overexpressed in various malignant tumors and play critical roles in tumor invasion and migration (41-43). In the present study, we examined whether EGCG exhibits its anti-invasion and anti-migration activity in SGT cells through $\beta 1$ integrin-mediated pathway. EGCG treatment inhibited the activation of its down-stream molecules such as FAK, AKT, and ERK as well as $\beta 1$ integrin itself. Moreover, MMP-2 and MMP-9 expression was also reduced by EGCG in a dose-dependent manner. ECGC has been also shown to inhibit the enzymatic activity of secreted MMP-2 and MMP-9 in human fibrosarcoma (44). Similarly, our result showed that EGCG treatment led to inhibition of enzymatic activity of MMP-2 and MMP-9 in SGT cells.

In conclusion, invasion and migration are dependent on production of MMP-2 and MMP-9 and their enzymatic activity through $\beta 1$ integrin-mediated pathway. EGCG inhibited effectively the invasion and migration of SGT cells, B1 integrin expression, activation of FAK, AKT, and ERK, and the MMP-2 and MMP-9 expression and their enzymatic activity of MMP-2 and MMP-9. Our results suggest that EGCG may exhibit beneficial effects on salivary gland tumor progression by inhibiting invasion and migration via $B 1$ integrin-mediated signaling pathway.

\section{Acknowledgements}

This study was supported by the Korea Science and Engineering Foundation (KOSEF) grant funded by the Korea government (MOST) (No. R13-2008-010-01001-0).

\section{References}

1. Etges A, Nunes FD, Ribeiro KC and Araujo VC: Immunohistochemical expression of retinoblastoma pathway proteins in normal salivary glands and in salivary gland tumours. Oral Oncol 40: 326-331, 2004.

2. Milano A, Longo F, Basile M, Iaffaioli RV and Caponigro F: Recent advances in the treatment of salivary gland cancers: emphasis on molecular targeted therapy. Oral Oncol 43: 729-734, 2007.

3. Prenen H, Kimpe $M$ and Nuyts S: Salivary gland carcinomas: molecular abnormalities as potential therapeutic targets. Curr Opin Oncol 20: 270-274, 2008.
4. Spitz MR, Tilley BC, Batsakis JG, Gibeau JM and Newell GR: Risk factors for major salivary gland carcinoma. A casecomparison study. Cancer 54: 1854-1859, 1984.

5. Preston-Martin S, Thomas DC, White SC and Cohen D: Prior exposure to medical and dental x-rays related to tumors of the parotid gland. J Natl Cancer Inst 80: 943-949, 1988.

6. Maxon HR, Saenger EL, Buncher CR, et al: Radiation-associated carcinoma of the salivary glands. A controlled study. Ann Otol Rhinol Laryngol 90: 107-108, 1981

7. Hsu YC, Lu HF, Huang CC, Hsu RF and Su CY: Malignant lymphoepithelial lesions of the salivary gland. Otolaryngol Head Neck Surg 134: 661-666, 2006.

8. Barnes L, Everson JW and Reichart P: World Health Organization classification of tumours. IARC Press, Lyon, 2005.

9. Spiro RH: Management of malignant tumors of the salivary glands. Oncology (Williston Park) 12: 671-683, 1998.

10. Dodd RL and Slevin NJ: Salivary gland adenoid cystic carcinoma: a review of chemotherapy and molecular therapies. Oral Oncol 42: 759-769, 2006.

11. Graham HN: Green tea composition, consumption and polyphenol chemistry. Prev Med 21: 334-350, 1992.

12. Yang GY, Liao J, Kim K, Yurkow EJ and Yang CS: Inhibition of growth and induction of apoptosis in human cancer cell lines by tea polyphenols. Carcinogenesis 19: 611-616, 1998.

13. Jung YD, Kim MS, Shin BA, et al: EGCG, a major component of green tea, inhibits tumour growth by inhibiting VEGF induction in human colon carcinoma cells. Br J Cancer 84: 844-850, 2001

14. Lim YC, Park HY, Hwang HS, et al: (-)-Epigallocatechin-3gallate (EGCG) inhibits HGF-induced invasion and metastasis in hypopharyngeal carcinoma cells. Cancer Lett 271: 140-152, 2008.

15. Ho YC, Yang SF, Peng CY, Chou MY and Chang YC: Epigallocatechin-3-gallate inhibits the invasion of human oral cancer cells and decreases the productions of matrix metalloproteinases and urokinase-plasminogen activator. J Oral Pathol Med 36: 588-593, 2007.

16. Kato K, Long NK, Makita H, et al: Effects of green tea polyphenol on methylation status of RECK gene and cancer cell invasion in oral squamous cell carcinoma cells. Br J Cancer 99: 647-654, 2008.

17. Kushima Y, Iida K, Nagaoka Y, et al: Inhibitory effect of (-)-epigallocatechin and (-)-epigallocatechin gallate against heregulin beta 1 -induced migration/invasion of the MCF- 7 breast carcinoma cell line. Biol Pharm Bull 32: 899-904, 2009.

18. Ishino A, Kusama K, Watanabe S and Sakagami H: Inhibition of epigallocatechin gallate-induced apoptosis by $\mathrm{CoCl} 2$ in human oral tumor cell lines. Anticancer Res 19: 5197-5201, 1999.

19. Kusama K, Jiang Y, Toguchi M, et al: Use of the monoclonal antibody M30 for detecting HSG cell apoptosis. Anticancer Res 20: $151-154,2000$.

20. Shrestha P, Sumitomo S, Lee CH, et al: Tenascin: growth and adhesion modulation-extracellular matrix degrading function: an in vitro study. Eur J Cancer B Oral Oncol 32B: 106-113, 1996.

21. Lin TH, Kuo HC, Chou FP and Lu FJ: Berberine enhances inhibition of glioma tumor cell migration and invasiveness mediated by arsenic trioxide. BMC Cancer 8: 58, 2008.

22. Lee KJ, Hwang SJ, Choi JH and Jeong HG: Saponins derived from the roots of Platycodon grandiflorum inhibit HT-1080 cell invasion and MMPs activities: regulation of NF-kappaB activation via ROS signal pathway. Cancer Lett 268: 233-243, 2008.

23. Bergers $G$ and Benjamin LE: Tumorigenesis and the angiogenic switch. Nat Rev Cancer 3: 401-410, 2003.

24. Kalluri R: Basement membranes: structure, assembly and role in tumour angiogenesis. Nat Rev Cancer 3: 422-433, 2003.

25. Jin $\mathrm{H}$ and Varner J: Integrins: roles in cancer development and as treatment targets. Br J Cancer 90: 561-565, 2004.

26. Sounni NE and Noel A: Membrane type-matrix metalloproteinases and tumor progression. Biochimie 87: 329-342, 2005.

27. Khan N and Mukhtar H: Multitargeted therapy of cancer by green tea polyphenols. Cancer Lett 269: 269-280, 2008.

28. Hung CF, Huang TF, Chiang HS and Wu WB: (-)-Epigallocatechin-3-gallate, a polyphenolic compound from green tea, inhibits fibroblast adhesion and migration through multiple mechanisms. J Cell Biochem 96: 183-197, 2005.

29. Arvelo F and Cotte C: Metalloproteinases in tumor progression. (Review). Invest Clin 47: 185-205, 2006. 
30. Pasco S, Brassart B, Ramont L, Maquart FX and Monboisse JC: Control of melanoma cell invasion by type IV collagen. Cancer Detect Prev 29: 260-266, 2005

31. Hynes RO: Integrins: bidirectional, allosteric signaling machines. Cell 110: 673-687, 2002.

32. Hemler ME, Mannion BA and Berditchevski F: Association of TM4SF proteins with integrins: relevance to cancer. Biochim Biophys Acta 1287: 67-71, 1996.

33. Morini M, Mottolese M, Ferrari N, et al: The alpha 3 beta 1 integrin is associated with mammary carcinoma cell metastasis, invasion, and gelatinase B (MMP-9) activity. Int J Cancer 87: 336-342, 2000.

34. Varner JA and Cheresh DA: Integrins and cancer. Curr Opin Cell Biol 8: 724-730, 1996.

35. Miranti CK and Brugge JS: Sensing the environment: a historical perspective on integrin signal transduction. Nat Cell Biol 4: E83-E90, 2002.

36. Sonoda Y, Watanabe S, Matsumoto Y, Aizu-Yokota E and Kasahara T: FAK is the upstream signal protein of the phosphatidylinositol 3-kinase-Akt survival pathway in hydrogen peroxide-induced apoptosis of a human glioblastoma cell line. J Biol Chem 274: 10566-10570, 1999.

37. Schlaepfer DD and Hunter T: Focal adhesion kinase overexpression enhances ras-dependent integrin signaling to ERK2/ mitogen-activated protein kinase through interactions with and activation of c-Src. J Biol Chem 272: 13189-13195, 1997.
38. Sankar S, Mahooti-Brooks N, Hu G and Madri JA: Modulation of cell spreading and migration by pp125FAK phosphorylation. Am J Pathol 147: 601-608, 1995.

39. Somanath PR, Kandel ES, Hay N and Byzova TV: Akt1 signaling regulates integrin activation, matrix recognition, and fibronectin assembly. J Biol Chem 282: 22964-22976, 2007.

40. Irie HY, Pearline RV, Grueneberg D, et al: Distinct roles of Akt 1 and Akt2 in regulating cell migration and epithelialmesenchymal transition. J Cell Biol 171: 1023-1034, 2005.

41. John A and Tuszynski G: The role of matrix metalloproteinases in tumor angiogenesis and tumor metastasis. Pathol Oncol Res 7: 14-23, 2001.

42. Johnson LL, Dyer R and Hupe DJ: Matrix metalloproteinases. Curr Opin Chem Biol 2: 466-471, 1998.

43. Westermarck $\mathbf{J}$ and Kahari VM: Regulation of matrix metalloproteinase expression in tumor invasion. FASEB J 13: 781-792, 1999.

44. Garbisa S, Sartor L, Biggin S, Salvato B, Benelli R and Albini A: Tumor gelatinases and invasion inhibited by the green tea flavanol epigallocatechin-3-gallate. Cancer 91: 822-832, 2001. 